\title{
Dentate Gyrus
}

National Cancer Institute

\section{Source}

National Cancer Institute. Dentate Gyrus. NCI Thesaurus. Code C32452.

A serrated strip of gray matter under the medial border of the hippocampus and in its depths. It is an archicortex which develops along the edge of the hippocampal fissure and which consists of molecular, granular, and polymorphic layers. 